\title{
Characterization of Alternaria alternata Causing Black Spot Disease of Pomegranate in Israel Using a Molecular Marker
}

Tami Gat, Orna Liarzi, Yulia Skovorodnikova, and David Ezra, Department of Plant Pathology and Weed Research, ARO The Volcani Center, P.O. Box 6, Bet Dagan 50250, Israel

\begin{abstract}
Gat, T., Liarzi, O., Skovorodnikova, Y., and Ezra, D. 2012. Characterization of Alternaria alternata causing black spot disease of pomegranate in Israel using a molecular marker. Plant Dis. 96:1513-1518.

Black spot disease of pomegranate is a relatively new disease in Israel that is caused by Alternaria alternata. The symptoms include black spots on leaves and fruit. Only the outer part of the fruit is damaged; the edible tissue remains unaffected. In this study, we obtained 50 isolates of A. alternata from infected pomegranate plants that were classified based on pathogenicity tests using detached leaves. Using an arbitrarily primed polymerase chain reaction, we identified one primer

(primer CAG) that reacted only with DNA of isolates that induced the most severe disease symptoms. Based on the sequence of the amplified fragment, we generated a specific primer (primer C) that recognizes these highly virulent isolates. Therefore, we suggest that primer $\mathrm{C}$ can be utilized as a molecular marker for the detection of A. alternata isolates that cause black spot disease of pomegranate.
\end{abstract}

Alternaria alternata (Fr.) Keissl. is a ubiquitous necrotrophic fungus. There are at least seven pathogenic variants of this fungus, each producing unique host-selective toxins (HSTs) and causing disease on specific host plants $(9,11,12)$. Nishimura et al. (14) distinguished between the following pathotypes of A. alternata: apple, citrus, Japanese pear, strawberry, tobacco, and tomato, which cause Alternaria blotch of apple, brown spot of citrus (two different HSTs), black spot of Japanese pear, Alternaria black spot of strawberry, brown spot of tobacco, and stem canker of tomato, respectively (14).

The native range of pomegranate (Punica granatum L.) spans from Iran to the Himalayas in northern India, and this crop has been cultivated throughout the Mediterranean region since ancient times (10). Due to increasing evidence for health-promoting effects of pomegranate $(10,18)$, the consumption of pomegranate fruit and juice has been increasing, as well as the amount of area dedicated to its cultivation (10).

Insects, fungi, and bacteria can target different parts of the pomegranate tree. The severity of diseases depends on the particular geographical region (10). In the eastern Mediterranean region, A. alternata is an important pathogen of pomegranate $(3,15,19)$. In Turkey, A. alternata causes lesions on leaves, flowers, and young fruit (15). Reports from Greece, India, Israel, and the United States describe black rot of the fruit core that begins at the calyx area while the hard rind retains its healthy appearance (19). Fruit with black rot can be identified based on skin color and their light weight. Black rot is a major pomegranate disease impacting production in California (23) and was reported to cause up to $50 \%$ fruit loss in Greece (19).

Recently, we reported on the appearance of novel symptoms of A. alternata in pomegranate orchards in Israel (3). These symptoms include black spots on leaves and fruit, ranging from a single lesion to lesions that cover more than $50 \%$ of the fruit surface, as

\section{Corresponding author: David Ezra, E-mail: dezra@ volcani.agri.gov.il}

* The $\boldsymbol{e}$-Xtra logo stands for "electronic extra" and indicates that Figures 2 and 5 appear in color online.

Accepted for publication 25 April 2012.

http://dx.doi.org/10.1094/PDIS-12-11-1041-RE

(C) 2012 The American Phytopathological Society well as chlorosis and the abscission of some leaves. Lesions begin to appear on all cultivars at the beginning of summer and are round on fruit and round to irregular on leaves. They are surrounded by a green-yellow halo. On fruit, the damage is restricted to the peel surface while the edible tissue remains unaffected (3). This is in contrast to black rot of pomegranate, in which the fruit rot is restricted to the internal area whereas the peel and leaves remains unaffected. Thus, A. alternata that causes black spot of pomegranate is different from the one that causes internal rot of pomegranate and other crops' Alternaria spp.-incited diseases (3).

A. alternata can be found as an epiphytic saprophyte on all parts of the plant without causing any damage. Isolation of A. alternata from plants does not indicate whether pathogenic isolates of this species are present $(2,4)$. Currently, the only method available for identification of pathogenic isolates is by pathogenicity tests, which can be time and labor consuming. Due to the increasing commercial importance of pomegranate and the desire to reduce the use of fungicides, a fast and simple method for early detection of A. alternata associated with infectious black spot is needed. Arbitrarily primed polymerase chain reaction (apPCR) is a simple and reproducible assay based on amplification of random genomic DNA segments with single primers of arbitrary nucleotide sequence. These primers detect polymorphisms in the absence of specific nucleotide sequence information, and the polymorphisms function as genetic marker $(5,7,20,22)$. The goal of this study was to generate a PCR-based molecular marker capable of detecting genomic DNA of virulent isolates of A. alternata causing black spot disease of pomegranate.

\section{Materials and Methods}

Fungal isolation. Symptomatic fruit, leaves, stems, and branches were collected in orchards located in the main cultivation area of pomegranate in Israel (Fig. 1; Table 1). Infected plant tissues were surface sterilized in $1 \%$ sodium hypochlorite solution for $1 \mathrm{~min}$ and rinsed twice in water. Using a sterile scalpel, tissue pieces composed of spots, halo, and surrounding healthy tissue were placed onto potato dextrose agar (PDA) (Acumedia) amended with tetracycline at $12 \mu \mathrm{g} / \mathrm{ml}$ (Sigma), and incubated at $25^{\circ} \mathrm{C}$. Mycelium from fungal colonies was transferred to new plates and left to grow for 5 to 7 days prior to macroscopic and microscopic identification. Single-spore fungal isolates were used for all experiments

Pathogenicity tests. Pathogenicity tests were done using detached leaves (50 isolates were initially screened). Selected isolates 
were tested for symptom induction on leaves (approximately 2 weeks old, at least three independent experiments), flowers (two independent experiments), and fruit (approximately 2 months old, two independent experiments). Leaves (five leaves were inoculated with four drops of each isolate), flowers (two to three flowers inoculated with four drops for each flower), and fruit (two to three fruit inoculated with four drops for each) were surface sterilized as described above, inoculated with drops $(10 \mu \mathrm{l})$ of conidial suspensions $\left(10^{6}\right.$ conidia/ml $)$ from each isolate, and placed in a moist chamber $\left(25^{\circ} \mathrm{C}\right)$. An isolate of A. alternata obtained from a fruit showing symptoms of black rot (isolate 83; Table 1) was used as a negative control (3).

Koch's postulates (two independent experiments) were done using 3- to 6-month-old 'Wonderful' and 'Shami' plants grown in the greenhouse at $25^{\circ} \mathrm{C}$ with a 14-h photoperiod. Plants (two to three plants for each isolate) were spray or drop inoculated with a conidial suspension $\left(10^{6}\right.$ conidia/ml $)$ obtained from eight selected isolates and covered with plastic bags. After symptom appearance, the fungus was reisolated from infected leaves as described above.

In planta pathogenicity tests (three independent experiments) were done as follows. Spore suspensions of selected A. alternata isolates were prepared from PDA plates by washing each plate with sterile double-distilled water $\left(\mathrm{ddH}_{2} \mathrm{O} ; 2\right.$ to $3 \mathrm{ml} /$ plate $)$. The suspension was then filtered through two layers of cheesecloth and diluted to a concentration of $10^{4}$ conidia/ml. Conidia from A. alternata isolate 83 from pomegranate black rot (3), isolate 3 from citrus, and isolate 6-1 from persimmon (Table 1) were used as controls. Three 6- to 8-month-old pomegranate plants were spray

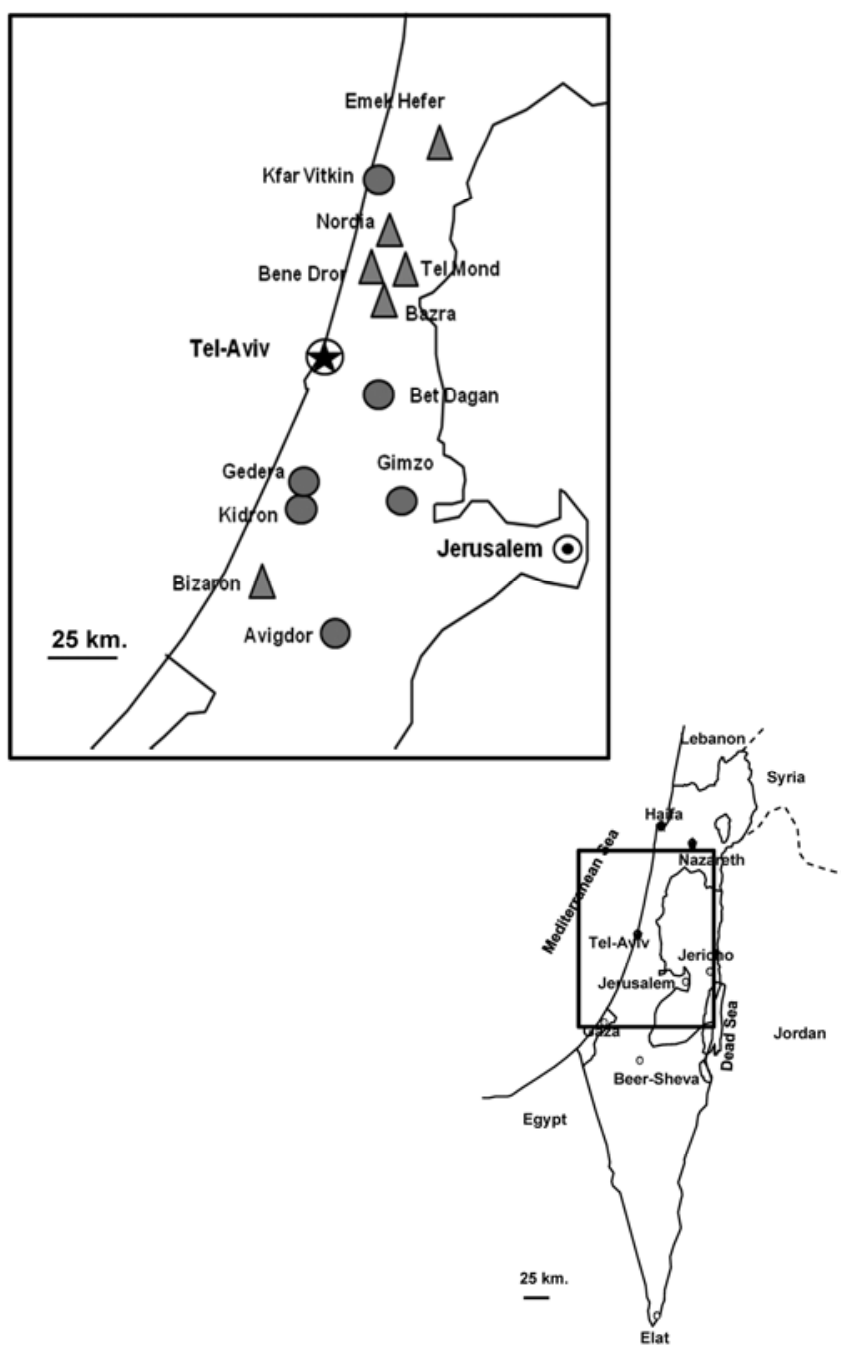

Fig. 1. Map of Israel. Inset: locations of the orchards tested in this study. Circles indicate pomegranate orchards, whereas triangles indicate other types of orchards. inoculated with conidial suspensions of each isolate and kept under conditions as described above for Koch's postulates.

Isolation of fungal DNA. Squares $\left(0.5 \mathrm{~cm}^{2}\right)$ from 7-day-old, single-spore mycelial cultures grown on PDA at $25^{\circ} \mathrm{C}$ were cut with a sterile scalpel and the agar was scraped from the bottom of each piece to exclude as much agar as possible. The pieces were homogenized in liquid nitrogen using a mortar and pestle. DNA was then extracted using the GenElute Plant Genomic DNA Miniprep Kit (Sigma) according to the manufacturer's instructions.

Amplification of internal transcribed spacer-5.8S rDNA, actin, and $\boldsymbol{\beta}$-tubulin genes. Sequences were obtained from five isolates: $32,47,49,57$, and 65 . The internal transcribed spacer (ITS) and $\beta$-tubulin sequences of isolate 47 were already published previously (GenBank accession numbers GQ240306 and GQ240308, respectively) (3). ITS regions were amplified using primers ITS1 and ITS4 (21) (Table 2). Parts of the actin and $\beta$-tubulin genes were amplified using primers ACT512F and ACT783R (1) or Bt1a and $\mathrm{Bt} 1 \mathrm{~b}(6)$, respectively (Table 2). Amplifications were done in a $25-\mu \mathrm{l}$ reaction mix containing $10 \mathrm{ng}$ of DNA, $1 \mu \mathrm{l}(10 \mu \mathrm{M})$ of each primer, dNTPs ( $2.5 \mathrm{mM}$ each), $2.5 \mu \mathrm{l}$ of reaction buffer, $0.125 \mu \mathrm{l}$ $(0.625 \mathrm{U})$ of DreamTaq DNA polymerase (Fermentas), and PCRgrade $\mathrm{ddH}_{2} \mathrm{O}$ (Fisher Scientific). Amplifications were performed in a Biometra Personal Cycler.

The PCR program for ITS was as follows: $96^{\circ} \mathrm{C}$ for $5 \mathrm{~min}$; followed by 35 cycles of $96^{\circ} \mathrm{C}$ for $45 \mathrm{~s}, 55^{\circ} \mathrm{C}$ for $45 \mathrm{~s}$, and $72^{\circ} \mathrm{C}$ for 1 min; and then $72^{\circ} \mathrm{C}$ for $5 \mathrm{~min}$. The PCR program for actin was similar to the one for ITS, except that the denaturizing temperature was $95^{\circ} \mathrm{C}$, the annealing temperature was $61^{\circ} \mathrm{C}$, and the number of cycles was 40 . The reaction program for $\beta$-tubulin was $95^{\circ} \mathrm{C}$ for 5 min; followed by 35 cycles of $95^{\circ} \mathrm{C}$ for $50 \mathrm{~s}, 54^{\circ} \mathrm{C}$ for $1 \mathrm{~min}$, and $72^{\circ} \mathrm{C}$ for $1 \mathrm{~min}$; and then $72^{\circ} \mathrm{C}$ for $5 \mathrm{~min}$. PCR products were examined by electrophoresis in a $1.0 \%$ agarose gel (17). The PCR products of ITS, actin, and $\beta$-tubulin were purified using the GFX PCR DNA and Gel Band Purification Kit (GE Healthcare) according to the manufacturer's instructions. Purified products were sent for direct PCR sequencing (Macrogen).

Sequences were submitted to GenBank. Sequences of isolates 47, 49, 57, 32, and 65 were deposited as accession numbers JN247825, JN247826, JN247827, JN247828, and JN247829 (ITS); JN247830, JN247831, JN247832, JN247833, and JN247834 ( $\beta$ tubulin); and JN247835, JN247836, JN247837, JN247838, and JN247839 (actin), respectively. The sequences obtained in this study were compared with those already present in the GenBank database using the BLAST software on the National Center for Biotechnology Information website (http://www.ncbi.nlm.nih.gov/ BLAST/).

apPCR. Amplification reactions in two independent experiments were done in a $25-\mu \mathrm{l}$ reaction mix as described above, except that only one primer (primer CAG) (16) was used (Table 2). The reaction program was as follows: $96^{\circ} \mathrm{C}$ for $5 \mathrm{~min}$; followed by 35 cycles of $96^{\circ} \mathrm{C}$ for $45 \mathrm{~s}, 63^{\circ} \mathrm{C}$ for $45 \mathrm{~s}$, and $72^{\circ} \mathrm{C}$ for $45 \mathrm{~s}$; and then $72^{\circ} \mathrm{C}$ for $5 \mathrm{~min}$. PCR products were separated in a $1.2 \%$ agarose gel and banding patterns were examined visually.

Design of primers specific for highly virulent isolates. A unique band, specific to highly virulent isolates, was gel eluted using the GFX PCR DNA and Gel Band Purification Kit (GE Healthcare) according to the manufacturer's instructions and cloned into the cloning vector pGEM-T Easy (Promega Corp.) according to the manufacturer's instructions. The ligated vector was transformed into competent Escherichia coli (DH5 $\alpha$; Novagen) and the plasmid was purified using the HiYield Plasmid Mini Kit (RBC Bioscience). The purified product was sequenced as described above. Primer $\mathrm{C}$ (Table 2) was designed based on the unique sequence and examined for its ability to specifically recognize highly virulent isolates. PCR reactions were done as for amplification of ITS except that primer $\mathrm{C}$ was used. The amplification program was $95^{\circ} \mathrm{C}$ for $5 \mathrm{~min}$; followed by 28 cycles of $95^{\circ} \mathrm{C}$ for $1 \mathrm{~min}, 64^{\circ} \mathrm{C}$ for $1 \mathrm{~min}$, and $72^{\circ} \mathrm{C}$ for $1 \mathrm{~min}$; and then $72^{\circ} \mathrm{C}$ for 5 min. PCR products were examined by gel electrophoresis and the product from one amplification was sequenced as described above. 


\section{Results}

Pathogenicity and virulence of A. alternata isolates from pomegranate using detached leaves, flowers, and fruit. Pathogenicity tests on detached leaves, flowers, and fruit revealed variability in disease severity among isolates. We classified isolates into four groups according to the severity of symptoms on detached leaves (Fig. 2A). Isolates that did not induce any visible symptoms were classified into virulence group 0 . Isolates that caused mild, moderate, or severe symptoms were classified into virulence groups 1, 2, and 3, respectively. For example, severe symptoms described lesions that spanned most of the leaf surface, while mild and moderate symptoms described lesions that were paler and smaller. Pathogenicity tests were also done on detached flowers (Fig. 2B) and fruit (Fig. 2C), and responses were different than on leaves. For example, isolate 32 induced very weak symptoms on leaves and no symptoms on flowers or fruit. In contrast, isolates 48 and 51 (Fig. 2) induced very severe symptoms on leaves, flowers, and fruit.

Sequence analysis of Alternaria black spot isolates from different virulence groups. ITS sequences (approximately $500 \mathrm{bp}$ ) of isolates 32, 47, 49, and 57, representing virulence groups 1 to 3 (Table 1), were identical to that of a pathogenic isolate of A. alternata previously submitted to GenBank (accession number FJ946480). The sequence of isolate 65 shared 98\% identity with the other isolates. Sequences of the partial $\beta$-tubulin gene (approximately $430 \mathrm{bp}$ ) were identical for all isolates and were identical with the A. alternata sequence in GenBank (accession number EU139350). Similarly, the partial actin sequences (approximately $200 \mathrm{bp}$ ) of all of the tested isolates were identical to each other regardless of their corresponding virulence group and were most similar (97\% identity) to that of an Alternaria sp. (accession number HQ413699). These results demonstrate that isolates with different levels of virulence share the same ITS, $\beta$-tubulin, and actin sequences.
apPCR of Alternaria black spot isolates. PCR reactions with the arbitrary primer CAG using template DNA of isolates representing all virulence groups revealed the presence of a fragment approximately $1,200 \mathrm{bp}$ in size only in virulence group 3 isolates (Fig. 3). The sequence of the amplified band was submitted to GenBank as accession number JN587345. DNA and protein sequences for this unique band shared similarity to hypothetical genes from Pyrenophora spp. published in GenBank (38\% coverage with $93 \%$ identity by blastn and $42 \%$ coverage with $56 \%$ identity by blastx to hypothetical genes from Pyrenophora teres and P. tritici, respectively). Arbitrary primers AGG and ACTG did not identify fragment patterns that were related to virulence and primer TGTC did not yield any product (data not shown).

Virulence-specific PCR analysis of Alternaria black spot isolates. Based on the sequence of the 1,200-bp band amplified by primer $\mathrm{CAG}$, we designed primer $\mathrm{C}$, which specifically recognized highly virulent isolates (i.e., isolates in virulence group 3; Fig. 4). Primer $\mathrm{C}$ also amplified DNA of fungal tissue that emerged from symptomatic fruit and induced mycelia and conidia typical of Alternaria spp., as shown previously (3). Primer C did not amplify DNA of A. radicina, A. dauci, A. brassicicola, and A. raphani

Table 2. Primers used in this study

\begin{tabular}{llc}
\hline Primer & \multicolumn{1}{c}{ Primer DNA sequence } & Reference \\
\hline ITS1 & 5' TCCGTAGGTGAACCTGCGGG 3' & 21 \\
ITS4 & 5' TCCTCCGCTTATTGATATGC 3' & 21 \\
ACT512F & 5' ATGTGCAAGGCCGGTTTCGC 3' & 1 \\
ACT783R & 5' TACGAGTCCTTCTGGCCCAT 3' & 1 \\
Bt1a & 5' TTCCCCCGTCTCCACTTCTTCATG 3' & 6 \\
Bt1b & 5' GACGAGATCGTTCATGTTGAACTC 3' & 6 \\
CAG & 5' CAGCAGCAGCAGCAG 3' & 16 \\
C_for & 5' ACCACCGCCACTAGATTCTG 3' & This study \\
C_rev & 5' GTTAGTCCCTGGTGCGATGT 3' & This study \\
\hline
\end{tabular}

Table 1. Isolates of Alternaria alternata collected from pomegranate and other fruit trees used in this study

\begin{tabular}{|c|c|c|c|}
\hline Location & Host & Source & Isolate number ${ }^{\mathrm{a}}$ \\
\hline Bene Dror & Nova $^{b}$ & Fruit & 3 \\
\hline Emek Hefer & Minneola $^{c}$ & Branch canker & 11 \\
\hline Bizron & Persimmon $^{\mathrm{d}}$ & Leaf & $6-1$ \\
\hline Nordia & Persimmon $^{\mathrm{d}}$ & Leaf & $8-1$ \\
\hline Tel Mond & White grapefruit ${ }^{\mathrm{e}}$ & Fruit & 9 \\
\hline Bazra & Red grapefruit $^{\mathrm{f}}$ & Fruit & 10 \\
\hline \multirow[t]{3}{*}{ Kefar Vitkin } & Wonderfulg & Leaf & $19^{1}, 23-27^{1}, 31^{1}, 32^{1}, 48^{3}$ \\
\hline & $\ldots$ & Fruit & $22^{1}, 28^{1}, 29^{2}, 30^{1}, 33^{1}, 34^{1}, 57^{2}$ \\
\hline & $\ldots$ & Branch & $20^{1}, 47^{3}$ \\
\hline \multirow[t]{2}{*}{ Gimzo } & $\mathrm{Akko}^{\mathrm{g}}$ & Leaf & $36^{1}, 37^{1}, 42^{1}$ \\
\hline & $\ldots$ & Fruit & $41^{1}, 49^{2}$ \\
\hline \multirow[t]{7}{*}{ Kidron } & Shirg & Fruit & $38^{1}, 39^{1}, 40^{1}$ \\
\hline & $105^{\mathrm{g}}$ & Fruit & $43^{3}, 51^{3}$ \\
\hline & 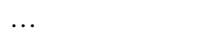 & Leaf & $44^{3}, 45^{1}$ \\
\hline & Rosh Peredg & Fruit & $64^{1}$ \\
\hline & $\ldots$ & Stem & $65^{1}$ \\
\hline & $\ldots$ & Leaf & $66^{0}$ \\
\hline & Wonderfulg & Fruit & $16^{1}, 17^{1}$ \\
\hline \multirow[t]{4}{*}{ Gedera } & $\mathrm{Akko}^{\mathrm{g}}$ & Fruit rot & $83^{0}, 84^{0}$ \\
\hline & Pashag & Leaf & $85^{1}, 86^{3}$ \\
\hline & Wonderful ${ }^{g}$ & Fruit & $87^{1}, 88^{1}$ \\
\hline & Pasha $^{\mathrm{g}}$ & Fruit & $89^{1}, 90^{1}$ \\
\hline \multirow[t]{2}{*}{ Avigdor } & Wonderful ${ }^{\mathrm{g}}$ & Fruit & $91^{0}, 92^{1}$ \\
\hline & $\ldots$ & Leaf & $93^{1}, 94^{1}$ \\
\hline Bet Dagan & Wonderful ${ }^{\mathrm{g}}$ & Leaf & $95^{1}, 96^{0}$ \\
\hline
\end{tabular}

a Superscript numerals indicate isolates classified to virulence groups as follows: group 0, showing no visible symptoms on detached leaves; group 1, showing mild symptoms on detached leaves; group 2, showing moderate symptoms on detached leaves; and group 3, showing severe symptoms on detached leaves.

${ }^{\mathrm{b}}$ Citrus clementina hort. ex Tanaka $\times($ C. reticulata Blanco $\times$ C. paradisi Macfad $)$.

${ }^{\mathrm{c}}$ Duncan $(C$. paradisi Duncan) $\times$ Dancy $(C$. reticulata Blanco) .

${ }^{\mathrm{d}}$ Diospyros kaki.

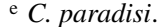

${ }^{\mathrm{f}}$ Star Ruby (C. paradisi).

g Pomegranate (Punica granatum). 
(data not shown), suggesting high specificity of the molecular marker.

Virulence of $A$. alternata isolates in inoculations of pomegranate plants. In inoculations of young pomegranate trees, only isolates of virulence group 3 (all six isolates) caused visible symptoms, whereas less virulent isolates did not induce any symptoms (Fig. 5). Concordantly, although for Koch's postulates we used isolates representing all virulence groups, only plants inoculated with isolates from virulence group 3 exhibited black spots on leaves approximately 1 week after inoculation (data not shown).

\section{Discussion}

Black spot of pomegranate in Israel was found to be caused by specific isolates of $A$. alternata that differ from isolates obtained from black-rot-infected fruit. A molecular marker was identified that differentiates highly virulent $A$. alternata isolates causing black spot of pomegranate from those causing no symptoms in planta. In contrast, the specificity of A. alternata pathotypes causing black rot is unknown mainly because, based on our experience, A. alternata isolated from any part of the pomegranate plant and from other plant species can cause internal rot when it is introduced into the fruit (D. Ezra, unpublished results).

A. alternata can be present as epiphytic saprophytes on different plant parts without causing any damage $(2,4)$. Therefore, the importance of our molecular marker is its ability to differentiate between isolates causing black spot and other isolates. Theoretically, the amplification of the marker within a mixture of isolates may be sufficient to determine the presence or absence of disease potential

A

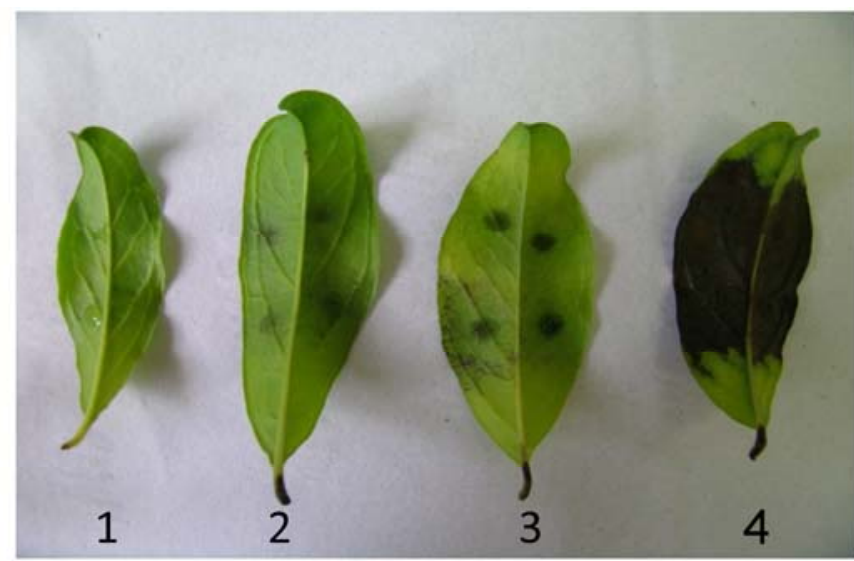

B
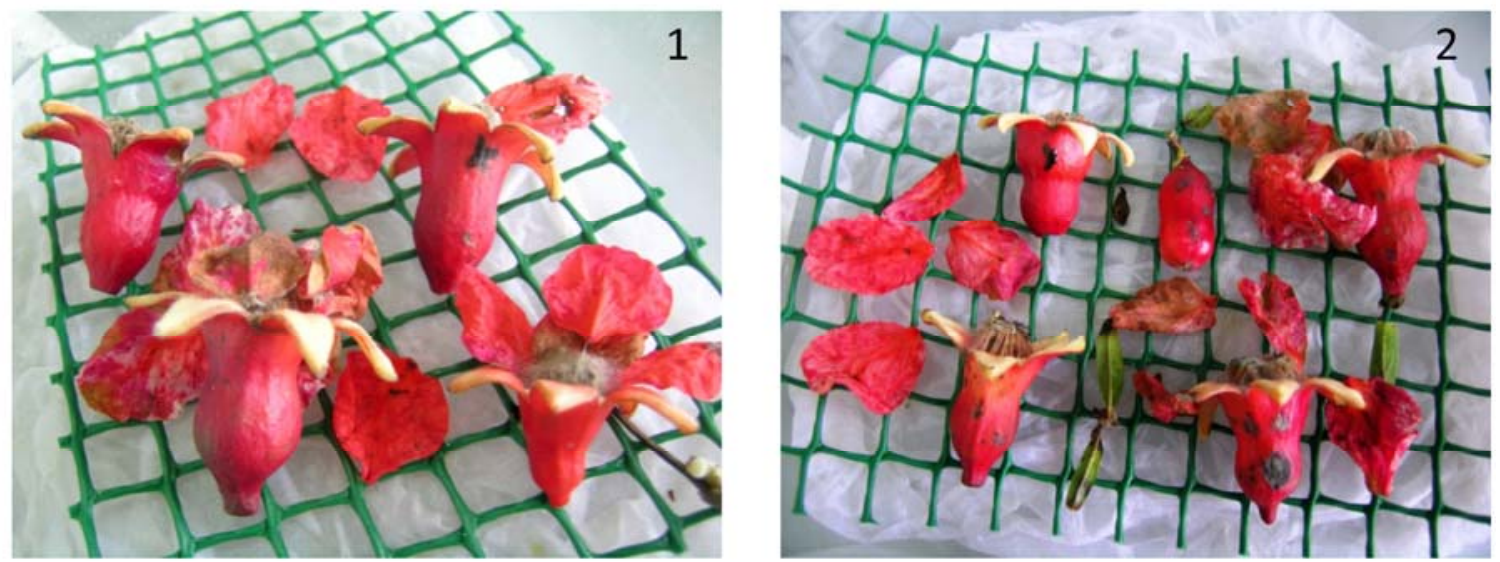

C

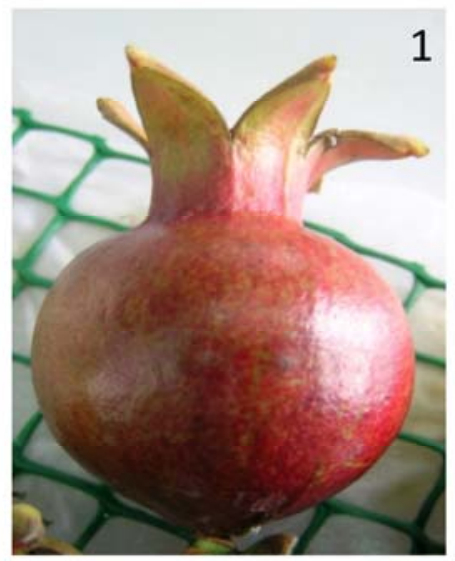

1

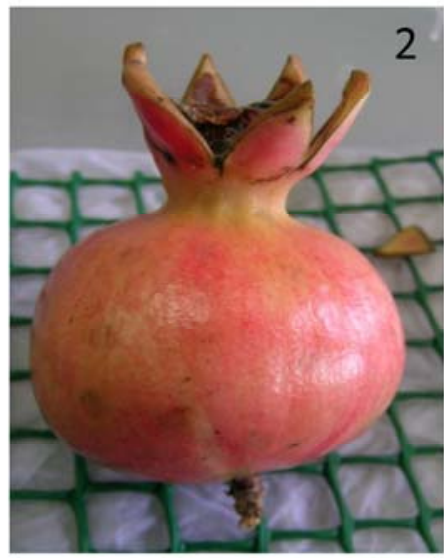

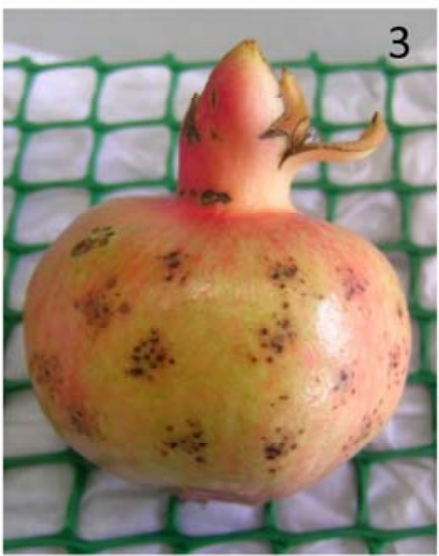

Fig. 2. Pathogenicity tests were performed on A, detached leaves; $\mathbf{B}$, flowers; and $\mathbf{C}$, fruit. $\mathbf{A}$, Detached leaves were drop inoculated with suspensions of conidia from isolates exhibiting 1, virulence group 0 (isolate 83); 2, virulence group 1 (isolate 32); 3, virulence group 2 (isolate 57); and 4, virulence group 3 (isolate 51 ). B, Detached flowers were drop inoculated with suspensions of conidia from isolates exhibiting 1, virulence group 1 (isolate 32) and 2, virulence group 3 (isolate 48). C, Harvested fruit were drop inoculated with suspensions of conidia from isolates exhibiting 1, virulence group 1 (isolate 32); 2, virulence group 2 (isolate 57 ); and 3 , virulence group 3 (isolate 51 ). All lesions were examined after 1 week. 
and, thereby, could avoid unnecessary pesticide applications in the orchard. Yet, more studies are needed to commercialize our molecular marker. These studies might include additional testing of the specificity of the molecular marker with a wider range of $A$. alternata isolates, testing of additional Alternaria spp., and also acquiring further information about the life cycle of the pathogen and epidemiology of the black spot disease.

Our findings revealed a discrepancy between the detached-leaf and whole-plant assays. A possible explanation is that detached leaves of pomegranate may be more susceptible to Alternaria infection due to senescence (13). Because in planta pathogenicity tests are much more labor and time consuming, we suggest the use of our virulence-specific molecular marker to identify the presence of the highly virulent, symptom-causing isolates.
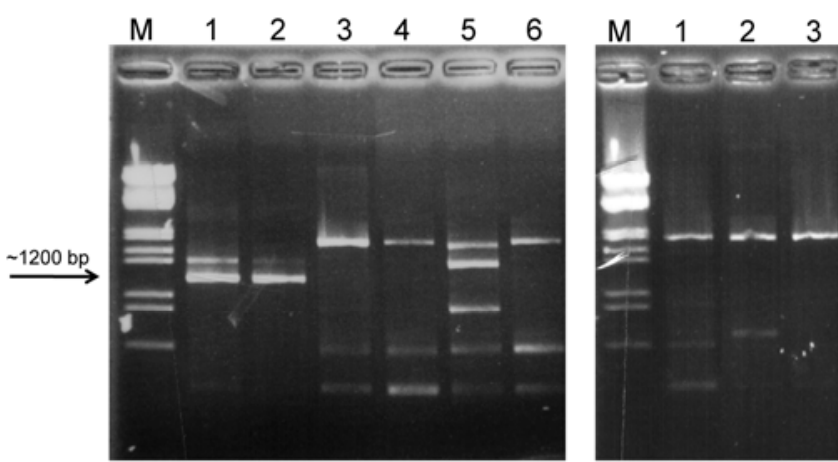

Fig. 3. Ethidium bromide-stained agarose gel showing genomic DNA of Alternaria alternata isolates from different virulence groups that were amplified using the arbitrary primer CAG. Left panel: lanes 1 and 2, virulence group 3 (isolates 51 and 48); lanes 3 and 4 , virulence group 2 (isolates 29 and 57 ); lanes 5 and 6 , virulence group 1 (isolates 28 and 38). Right panel: a control gel; lane 1, virulence group 0 (isolate 83); lanes 2 and $3, A$. alternata isolates from citrus and persimmon (isolates 3 and 6-1). Lane M, lambda DNA/EcoRI + HindllI marker. The arrow indicates the presence of a fragment approximately $1,200 \mathrm{bp}$ in size unique to virulence group 3 isolates.
Among the 50 isolates of A. alternata obtained from infected plant parts, only 6 induced black spot symptoms when tested on whole plants. A possible explanation for this is that saprophytic isolates were located by chance near the infected tissue. Another possibility is that the highly virulent isolates infected the plant and caused lesions that were subsequently colonized by nonvirulent isolates.

Our specific molecular marker for highly virulent, pomegranate black-spot-causing isolates of A. alternata is based on an approximately 1,200-bp sequence that appears to be unique to isolates that cause black spot symptoms of pomegranate. This suggests a genetic difference between highly virulent and less- or non-virulent isolates. Because the sequence shared little homology with any of the sequences in GenBank, it is unknown if this sequence encodes

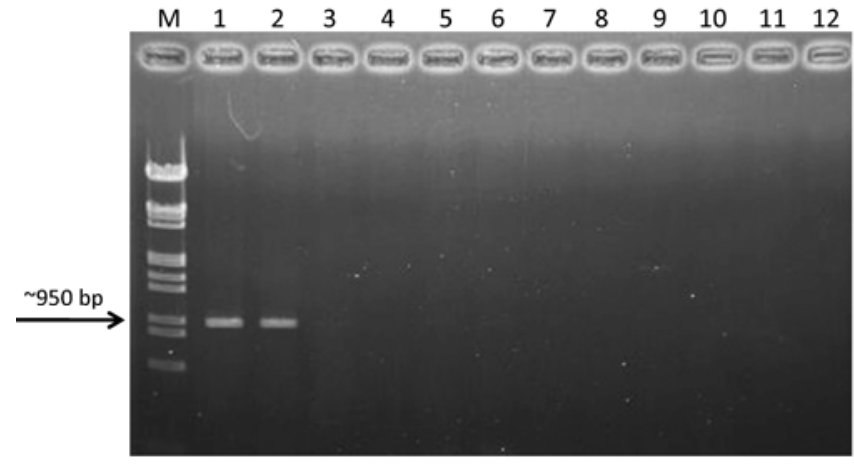

Fig. 4. Ethidium bromide-stained agarose gel showing genomic DNA of Alternaria alternata isolates from different virulence groups that were amplified using primer C. Lanes 1 and 2, virulence group 3 (isolates 48 and 51); lanes 3-5, virulence group 2 (isolates 29, 49 and 57); lanes 6-9, virulence group 1 (isolates 25, 34, 23 and 36); lane 10, virulence group 0 (isolate 83); lanes 11 and 12, A. alternata isolates from citrus and persimmon (isolate 3 and 6-1). Lane M, lambda DNA/EcoRI + HindllI marker. The arrow indicates the presence of a fragment approximately 950 bp in size unique to virulence group 3 isolates.
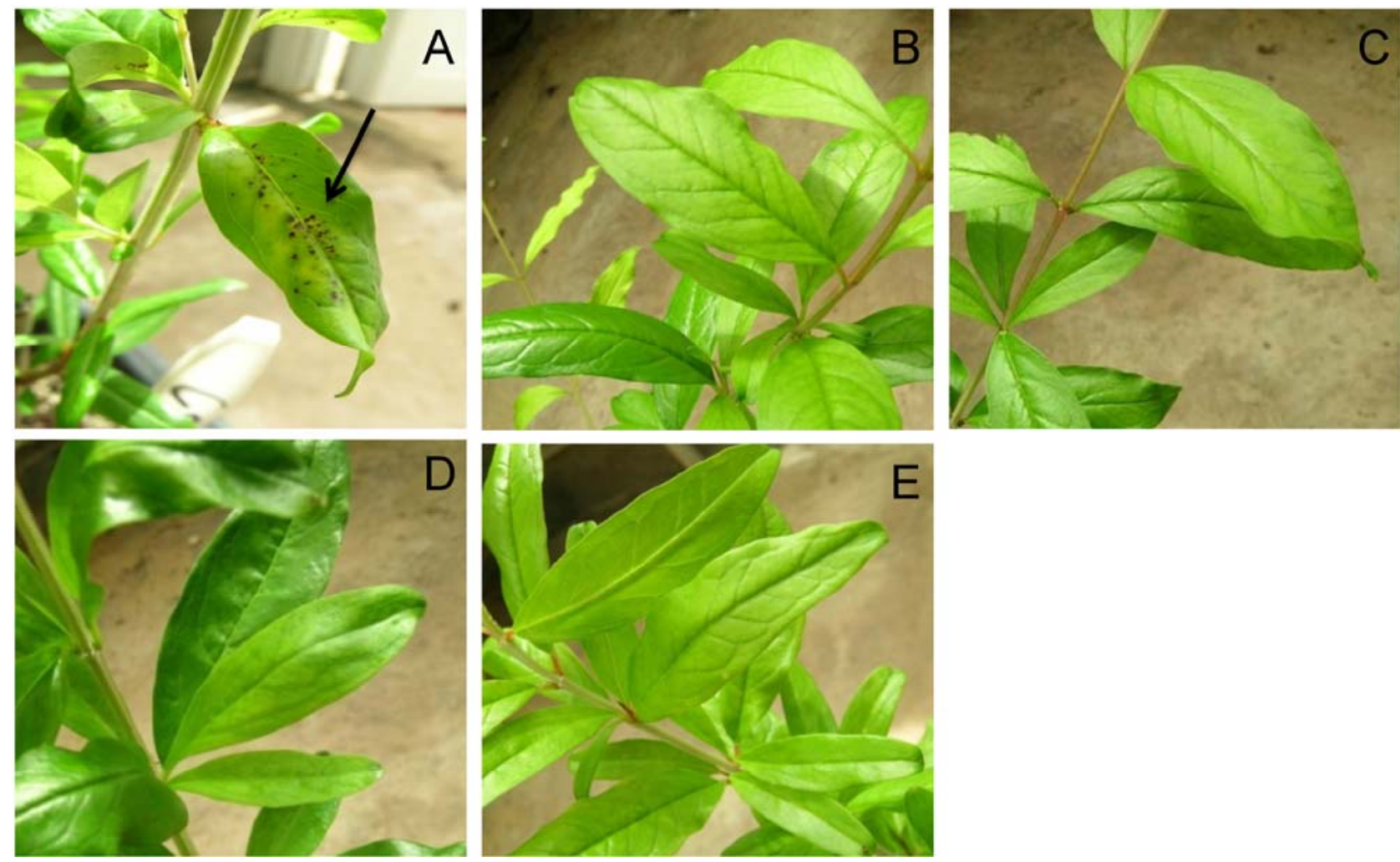

Fig. 5. Pathogenicity tests in planta. Young pomegranate trees were spray inoculated with suspensions of conidia from isolates that exhibited $\mathbf{A}$, virulence group 3 (isolate 51); B, virulence group 2 (isolate 57); C, virulence group 1 (isolate 36); D, virulence group 0 (isolate 83); and E, Alternaria alternata isolates collected from persimmon (isolates 6-1). Lesions were examined after 1 week. 
a gene and, therefore, our findings add little to the understanding of the role it plays. We can speculate that this unique sequence might encode a gene that plays a role in pathogenicity and virulence; for example, in the biosynthesis of a toxin or in other plantpathogen interactions. Alternatively, this sequence might be involved in regulating genes that are involved in pathogenicity. It should be noted that arbitrary primer GACAC (8) also amplified a fragment approximately $1,100 \mathrm{bp}$ in size only in virulence group 3 isolates (data not shown). However, primer I, which was designed based on the sequence of this fragment, failed to amplify DNA of A. alternata isolated from black spot on symptomatic fruit (data not shown). Therefore, we did not do any further work with primer I.

\section{Acknowledgments}

This work was financed by the Fruit Marketing Board grant of Israel, grant number 132-1326-09. We thank I. Kosto and R. Lambez from the Ministry of Agriculture and Rural Development Extension Service for his help. We also thank Mrs. Ronit Kohen for supplying Alternaria sp. used in this study.

\section{Literature Cited}

1. Carbone, I., and Kohn, L. M. 1999. A method for designing primer sets for speciation studies in filamentous ascomycetes. Mycologia 91:553-556.

2. Domsch, K. H., Gams, W., and Anderson, T. H. 1980. Compendium of Soil Fungi. Academic Press, New York.

3. Ezra, D., Gat, T., Skovorodnikova, Y., Vardi, Y., and Kosto, I. 2010. First report of Alternaria black spot of pomegranate by Alternaria alternata in Israel. Aust. Plant Dis. Notes 5:1-2.

4. Farr, D. F., Bills, G. F., Chamuris, G. P., and Rossman, A. Y. 1989. Fungi on Plant and Plant Products in the United States. American Phytopathological Society, St. Paul, MN.

5. Freeman, S., Pham, M., and Rodriguez, R. J. 1993. Molecular genotyping of Colletotrichum species based on arbitrarily primed PCR, A + T-rich DNA and nuclear DNA analyses. Exp. Mycol. 17:309-322.

6. Glass, N. L., and Donaldson, G. C. 1995. Development of primer sets designed for use with the PCR to amplify conserved genes from filamentous ascomycetes. Appl. Environ. Microbiol. 61:1323-1330.

7. Gupta, M., Chyi, Y.-S., Romero-Severson, J., and Owen, J. L. 1994. Amplification of DNA markers from evolutionarily diverse genomes using single primers of simple-sequence repeats. Theor. Appl. Genet. 89:9981006.

8. Gupta, M., and Filner, P. 1991. Microsatellites amplify highly polymorphic DNA bands in SPAR of plant DNA. Abstract 1705. International Society for Plant Molecular Biology, Tucson, AZ.
9. Hatta, R., Ito, K., Hosaki, Y., Tanaka, T., Tanaka, A., Yamamoto, M., Akimitsu, K., and Tsuge, T. 2002. The conditionally dispensable chromosome controls host-specific pathogenicity in the fungal plant pathogen Alternaria alternata. Genetics 161:59-70.

10. Holland, D., Hatib, K., and Bar-Ya'akov, I. 2009. Pomegranate: botany, horticulture, breeding. Hortic. Rev. 35:127-192.

11. Ito, K., Tanaka, T., Hatta, R., Tamamoto, M., Akimitsu, K., and Tsuge, T. 2004. Dissection of the host range of the fungal plant pathogen Alternaria alternata by modification of secondary metabolism. Mol. Microbiol. 52:399-411.

12. Kohmoto, K., Akimitsu, K., and Otani, H. 1991. Correlation of resistance and susceptibility of citrus to Alternaria alternata with sensitivity to hostspecific toxins. Phytopathology 81:719-722.

13. Miller, B. L., and Huffaker, R. C. 1985 Differential induction of endoproteinases during senescence of attached and detached barley leaves. Plant Physiol. 78:442-446

14. Nishimura, S., and Kohmoto, K. 1983. Host-specific toxins and chemical structures from Alternaria species. Annu. Rev. Phytopathol. 21:87-116.

15. Pala, H., Tatli, A., Yilmaz, C., and Özgüven, A. I. 2009. Important disease of pomegranate fruit and control possibilities in Turkey. Acta Hortic. (ISHS) 818:285-290

16. Rodriguez, R. J., and Yoder, O. C. 1991. A family of conserved repetitive DNA elements from the fungal plant pathogen Glomerella cingulata (Colletotrichum lindemuthianum). Exp. Mycol. 15:232-242.

17. Sambrook, J., and Russell, D. W. 2001. Molecular Cloning: A Laboratory Manual, 3rd ed. Cold Spring Harbor Laboratory Press, Cold Spring Harbor, NY.

18. Seeram, N. P., Schulman, R. N., and Heber, H. 2006. Pomegranate: Ancient Roots to Modern Medicine. CRC Press, Taylor \& Francis Group, Boca Raton, FL.

19. Tziros, G. T., Lagopodi, A. L., and Tzavella-Klonari, K. 2007. Alternaria alternata fruit rot of pomegranate (Punica granatum) in Greece. New Dis. Rep. 15:14.

20. Welsh, J., and McClelland M. 1990. Fingerprinting genomes using PCR with arbitrary primers. Nucleic Acids Res. 18:7213-7218.

21. White, T. J., Bruns, T., Lee, S., and Taylor, J. W. 1990. Amplification and direct sequencing of fungal ribosomal RNA genes for phylogenetics. Pages 315-322 in: PCR Protocols: A Guide to Methods and Applications. M. A. Innis, D. H. Gelfand, J. J. Sninsky, and T. J. White, eds. Academic Press Inc., New York.

22. Williams, J. G. K., Kubelik, A. R., Livak, K. J., Rafalski, J. A., and Tingey, S. V. 1990. DNA polymorphisms amplified by arbitrary primers are useful as genetic markers. Nucleic Acids Res. 18:6531-6535.

23. Zhanga, L., and McCarthya, M. J. 2012 Black heart characterization and detection in pomegranate using NMR relaxometry and MR imaging. Postharvest Biol. Technol. 67:96-101. 